\title{
Vaginal discharge during pregnancy and associated adverse maternal and perinatal outcomes
}

\author{
Meharunnissa Khaskheli ${ }^{1}$, Shahla Baloch ${ }^{2}$, \\ Aneela Sheeba Baloch ${ }^{3}$, Syed Ghulam Sarwar Shah ${ }^{4}$
}

\begin{abstract}
Objectives: To observe the effects of vaginal discharge during pregnancy on maternal and fetal outcomes. Methods: This observational study was undertaken form June 2018 to 31 May 2019 period in the Department of Obstetrics and Gynaecology at Liaquat University of Medical and Health Sciences hospital Jamshoro Unit IV. Data were collected from a convenience sample of 85 pregnant women. All the pregnant women with vaginal discharge were included in the study, while the women with bleeding and other medical disorders during pregnancy were excluded. Data was analyzed.

Results: Women's mean age as $27.4( \pm 4.7)$ years and most were $28-35$ weeks pregnant $(n=29,34 \%)$ and primigravida $(n=35,41 \%)$. Seventy six women $(89 \%)$ presented with vaginal discharge while nine women $(11 \%)$ reported no vaginal discharge. Of those with vaginal discharge,53 women (69.7\%) had vaginal infections: bacterial vaginosis $(n=21,39.6 \%)$, vaginal candidiasis $(n=17,32.1 \%)$ and vaginal trichomoniasis $(n=15,28.3 \%)$. Pathological vaginal discharge (PVD) was associated with vaginal irritation $(n=30, p<0.0001)$, vaginal pain $(n=50, p<0.0001)$, fever $(n=12, p=0.015)$, uterine contractions $(n=31, p<0.0001)$, premature membrane rupture $(n=29, p<0.0001)$, abortion $(n=13, p=0.009)$, pre-term delivery $(n=24, p<0.0001)$ and post-partum endometritis $(n=19, p=0.0006)$. PVD was associated with neonatal outcomes i.e. low birth weight $(n=24, p<0.0001)$, low Apgar score at birth $(n=22, p=0.0001)$, neonatal respiratory distress syndrome $(\mathrm{n}=21, \mathrm{p}=0.0002)$, neonatal intensive care hospitalisation $(\mathrm{n}=20, \mathrm{p}=0.002)$ and early neonatal death $(\mathrm{n}=16$, $\mathrm{p}=0.003)$.
\end{abstract}

Conclusion: Pathological vaginal discharge (PVD) during pregnancy is more frequent and is associated with adverse maternal and perinatal outcomes.

KEYWORDS: Feto-maternal complications, Pregnancy outcomes, Pregnant women, Vaginal discharge.

How to cite this:

doi: https://doi.org/10.12669/pjms.37.5.4187

Khaskheli M, Baloch S, Baloch AS, Shah SGS. Vaginal discharge during pregnancy and associated adverse maternal and perinatal outcomes. Pak J Med Sci. 2021;37(5):1302-1308. doi: https://doi.org/10.12669/pjms.37.5.4187

This is an Open Access article distributed under the terms of the Creative Commons Attribution License (http://creativecommons.org/licenses/by/3.0), which permits unrestricted use, distribution, and reproduction in any medium, provided the original work is properly cited.

\section{INTRODUCTION}

Vaginal discharge (VD) is a frequent gynaecological complaint in women during

Correspondence:

Meharunnissa Khaskheli,

Department of Obstetrics and Gynecology,

Liaquat University of Medical and Health Sciences,

Liaquat University Hospital,

Jamshoro, Hyderabad, 71000,

Sindh, Pakistan.

E-mail: khaskhelimn@yahoo.com

* Received for Publication:

* Revision Received:

* Revision Accepted:
January 21, 2021

April 26, 2021

May 5, 2021 their reproductive life and especially during pregnancy. ${ }^{1,2}$ Women however could not generally differentiate between normal (physiological) and abnormal (pathological) vaginal discharge. ${ }^{3}$ Proper diagnosis of VD requires clinical examination and laboratory investigations. ${ }^{4}$ Normal vaginal discharge, also known as leucorrhoea, is thin, clear or milky white fluid with a mild odor. It is one of the earliest signs of pregnancy and it progressively increases in amount and continues throughout the pregnancy whereas pathological vaginal discharge (PVD) varies in color from dirty white to yellowish green and it may be foul smelling. PVD commonly results due to vaginal infections such as bacterial 
vaginosis, trichomonas vaginalis and vaginal candidiasis or candidial vaginitis, which is also known as vulvovaginal candidiasis. ${ }^{2}$

Bacterial vaginosis (BV) is a common vaginal infection caused by the imbalance of microorganisms of vulvovaginal area. Although mostly asymptomatic, BV increases risk of sexually transmitted infections (STI), HIV/ AIDS, trichomonas vaginalis and vaginal candidiasis., ${ }^{5,6}$ It is also associated with adverse pregnancy outcomes i.e., premature rupture of membranes, preterm labor and delivery, and postpartum endometritis. Vaginal candidiasis (VC) is the commonest fungal infection of vagina, which is caused by the overgrowth of candida species. ${ }^{7}$ These are the flora that normally present in the lower genital tract in healthy and asymptomatic women. ${ }^{8}$ In pregnant women, candida albicans is the most common type of vaginal candida species followed by candida glabrata.VC is commonly associated with VD, which is whitish in color. The rate of VC is higher in women treated with broad spectrum antibiotics and those who are pregnant, diabetic and immune suppressed such as HIV/ AIDS patients. Vaginal candidiasis is associated with vaginal pain, difficult or painful sexual intercourse and vulvovaginal irritation and itching. It is also associated with pregnancy complications such as abortion, premature birth, and low birth weight.

Trichomonas vaginalis (TV) is a parasitic infection of vagina caused by the flagellated parasitic protozoan called Trichomonas vaginalis. It affects women in their reproductive life and pregnancy and it is the most common non-viral STI globally. Symptoms of TV in women include VD that is often yellow-green, diffuse and malodorous.TV is associated with dysuria, itching, vulvar irritation, abdominal pain, pelvic inflammatory disease and poor birth outcomes e.g., premature rupture of membranes, preterm delivery and low birth weight. ${ }^{9}$

BV, VC and TV affect about $6 \%$ women. ${ }^{10}$ All of these infections are associated with $\mathrm{VD}$ and may lead to vaginal dysbiosis (abnormal vaginal microbiota) during early stages of pregnancy which is commonly associated with adverse pregnancy outcomes. ${ }^{11}$ About half of pregnant women with PVD experience pruritus (itching), malodour (very unpleasant smell), dysuria (painful or difficult urination), and dyspareunia (difficult or painful sexual intercourse) In addition, VD is associated with psychological and mental disorders. ${ }^{12}$ Vaginal infections and associated VD are more prevalent in women of low literacy poor socio-economic background and living in lower and middles income countries such as Pakistan. Pathological vaginal discharge, especially in pregnant women, is an important public health issue due to its association not only with socio-psychological impacts during pregnancy but also due to its association with adverse maternal and foetal outcomes as mentioned above. There is therefore need for further research on VD in pregnant women especially those of lower socio-income background and living in lower and middle income countries such as Pakistan where there is a higher prevalence of vaginal candidiasis and bacterial vaginosis during pregnancy. ${ }^{13}$ The primary objective of this study was to differentiate between normal (physiological) and abnormal (pathological) VD during pregnancy. The secondary objective was to study whether PVD was associated with adverse maternal and perinatal outcomes.

\section{METHODS}

This observational study was conducted in Department of Obstetrics and Gynaecology at Liaquat University of Medical and Health Sciences hospital Jamshoro Unit IV. All pregnant women with complaint of VD were invited to the study. All pregnant women with threatened abortion, cervical incompetence, placental abnormalities, history of (Sexually transmitted infection) STI and treatment at STI clinics were excluded from the study. The subjected study population were recruited by convenience sampling of 85 pregnant women from June 1st 2018 to 31st May 2019. All women were recruited after taking their informed written consent. This study was approved (Ref: LUMHS/REC/-768, Dated: 2505-2018) by the research ethics committee of university. These women had regular antenatal visits, delivered in the hospital and were followed in the period of puerperium. They were evaluated thoroughly by taking detailed history, clinical examination and investigations. For every woman, three samples of VD were taken for laboratory investigations. The first sample was stored in a vial with $95 \%$ alcohol for cytological examination that sample was taken from squamocolumnar junction of cervix to exclude cervical pathology like CIN as those who had perception for vaginal discharge can have cause of discharge related to cervix; the second sample was utilized in the amine test; and the third sample was taken with a cotton swab, which was immersed in normal saline ( $1 \mathrm{ml}$, in sterile glass) for direct examination. The samples were sent to Pathological Diagnostic Research Centre for pathological examination and report. For candidiasis and trichomoniasis, direct microscopically examination 
Table-I: Participants' demographic and gestational characteristics ( $N=85)$.

Vaginal discharge

\begin{tabular}{|c|c|c|c|c|c|c|}
\hline & \multirow[b]{2}{*}{ Number } & \multirow[b]{2}{*}{ Percentage } & \multirow{2}{*}{ No } & \multicolumn{2}{|c|}{ Yes } & \multirow{2}{*}{$P$ value } \\
\hline & & & & Pathological & Physiological & \\
\hline Age & & & & & & 0.228 \\
\hline $20-25$ years & 32 & 37.7 & 3 & 17 & 12 & \\
\hline 26-31 years & 34 & 40.0 & 5 & 24 & 5 & \\
\hline 32-37 years & 19 & 22.3 & 1 & 11 & 7 & \\
\hline Gestational period & & & & & & 0.124 \\
\hline $8-14$ weeks & 15 & 17.6 & 2 & 5 & 8 & \\
\hline 15-21 weeks & 17 & 20 & 3 & 9 & 5 & \\
\hline 22-27 weeks & 24 & 28.2 & 3 & 16 & 5 & \\
\hline 28-35 weeks & 29 & 34.1 & 1 & 22 & 6 & \\
\hline Parity & & & & & & 0.566 \\
\hline Primigravida & 35 & 41.2 & 4 & 20 & 11 & \\
\hline Para 2-4 & 34 & 40.0 & 5 & 21 & 8 & \\
\hline Para 5 and above & 16 & 18.8 & 0 & 11 & 5 & \\
\hline
\end{tabular}

was taken as the gold standard for seeing hyphae and flagellate. For diagnosis of bacterial vaginosis, the Amsel criteria were taken as the gold standard. The diagnosis of bacterial vaginosis was confirmed by the presence of three of following four conditions i.e., vaginal discharge, vaginal $\mathrm{pH}>4.5$, positive result in the amine test and presence of clue cells on microscopy. These women were given treatment according to the cause.

Study variables, included participant's age, parity, gestation period, vaginal discharge, associated complaints of vaginal irritation and pain, smell, true onset of labor pains as well as presence of any existing maternal, pregnancy and neonatal problems.

Data was collected on predesigned proforma and analyzed by frequencies and descriptive statistics for continuous variables while categorical variables were analyzed with Chi Square tests for statistically significant differences between the observed and expected frequencies between two or more categories. P-value $\leq 0.05$ was considered as statistically significant. There were no missing values. Data were analyzed in the SPSS, version 23 for Windows (IBM Corp 2015).

\section{RESULTS}

Demographic and gestation characteristics: In total, 85 pregnant women who took part in this study. Women's age varied between 20 and 37 years (mean age $=27.4 \pm 4.7$ years). Majority of women were 26-31 years old ( $\mathrm{n}=34,40 \%), 28-35$ weeks pregnant $(\mathrm{n}=29,34 \%)$ and primigravida $(\mathrm{n}=35,41 \%)($ Table-I).

Out of 85 pregnant women who presented with vaginal discharge, seventy-six women $(89 \%)$ had VD on clinical examination, while nine women $(11 \%)$ had no obvious vaginal discharge. Laboratory examination of VD samples confirmed presence of vaginal infections in 53 women i.e., bacterial vaginosis $(\mathrm{n}=21,39.6 \%)$, candidiasis $(n=17,32.1 \%)$, and trichomoniasis $(n=15,28.3 \%)$, these cases were declared as PVD (Table-II). No growth of any pathogenic organism was found in the remaining 23 samples, which were declared as normal VD (Table-II). Normal VD was watery in color $(n=23,100 \%)$, a slight stain in the quantity $(n=22,95.65 \%)$ and odorless $(n=23,100 \%)$ whereas pathological discharge was mostly yellowish curd like in color $(n=17,32.1 \%)$, soaking clothes in the quantity $(n=35,66 \%)$ and foul smelling $(n=28$, $52.8 \%$ ) Compared to women with normal vaginal discharge, a higher proportion of women with PVD was statistically significantly associated with vaginal irritation $(\mathrm{n}=30, \mathrm{p}<0.0001)$, vaginal pain $(n=50, p<0.0001)$, fever $(n=12, p=0.015)$ (Table-II).

Compared to women with normal vaginal discharge, a higher proportion of women with PVD was statistically had significant rate of preterm uterine contractions $(n=31$, $\mathrm{p}<0.0001)$, premature membrane rupture $(\mathrm{n}=29$, 
Meharunnissa Khaskheli et al.

Table-II: Vaginal discharge its types, characteristics, associated symptoms and laboratory investigation reports ( $\mathrm{N}=85$ ).

\begin{tabular}{|c|c|c|c|c|}
\hline \multirow{3}{*}{ Vaginal discharge } & & \multicolumn{3}{|c|}{ Vaginal discharge } \\
\hline & & \multirow{2}{*}{$\begin{array}{l}\text { No obvious } \\
\text { discharge only } \\
\text { perception }\end{array}$} & \multicolumn{2}{|c|}{ Yes } \\
\hline & & & $\begin{array}{c}\text { Normal physiological } \\
\text { discharge }\end{array}$ & $\begin{array}{l}\text { Pathological } \\
\text { discharge }\end{array}$ \\
\hline & & Count (\%) & Count $(\%)$ & Count (\%) \\
\hline & & $9(10.6)$ & $23(27.05)$ & $53(62.35)$ \\
\hline \multicolumn{5}{|c|}{ Physical characteristics } \\
\hline \multicolumn{5}{|l|}{ Colour } \\
\hline No discharge & & $9(10.6)$ & 0 & 0 \\
\hline Watery & & 0 & $23(27.1)$ & $11(12.9)$ \\
\hline Yellowish curd like & & 0 & 0 & $17(20)$ \\
\hline Frothy & & 0 & 0 & $12(14.1)$ \\
\hline Muddy & & 0 & 0 & $13(15.3)$ \\
\hline \multicolumn{5}{|l|}{ Quantity } \\
\hline No discharge & & $9(10.6)$ & 0 & 0 \\
\hline Slight stain & & 0 & $22(25.9)$ & $6(7.0)$ \\
\hline Soaking clothes & & 0 & $1(1.2)$ & $35(41.2)$ \\
\hline Copious in amount & & 0 & 0 & $12(14.1)$ \\
\hline \multicolumn{5}{|l|}{ Odour } \\
\hline No discharge & & $9(10.6)$ & 0 & 0 \\
\hline Odourless & & 0 & $23(27.1)$ & $11(12.9)$ \\
\hline Fishy odour & & 0 & 0 & $14(16.5)$ \\
\hline Foul smelling & & 0 & 0 & $28(32.9)$ \\
\hline \multicolumn{5}{|l|}{ Associated Symptoms } \\
\hline $\begin{array}{l}\text { Vaginal Irritation } \\
\text { a. Yes } \\
\text { b. No }\end{array}$ & $\begin{array}{l}31(36.5) \\
54(63.5)\end{array}$ & $\begin{array}{c}0 \\
9(10.6)\end{array}$ & $\begin{array}{c}1(1.17) \\
22(25.88)\end{array}$ & $\begin{array}{l}30(35.29) \\
23(27.05)\end{array}$ \\
\hline $\begin{array}{l}\text { Vaginal pain } \\
\text { a. Yes } \\
\text { b. No }\end{array}$ & $\begin{array}{l}56(65.88) \\
29(34.11)\end{array}$ & $\begin{array}{l}2(2.35) \\
7(8.23)\end{array}$ & $\begin{array}{c}4(4.70) \\
19(22.35)\end{array}$ & $\begin{array}{c}50(58.82) \\
3(3.52)\end{array}$ \\
\hline $\begin{array}{l}\text { Fever } \\
\text { a. Yes } \\
\text { b. No }\end{array}$ & $\begin{array}{l}12(14.1) \\
73(85.9)\end{array}$ & $\begin{array}{c}0 \\
9(10.6)\end{array}$ & $\begin{array}{c}0 \\
23(27.05)\end{array}$ & $\begin{array}{l}12 \text { (14.11) } \\
41(48.23)\end{array}$ \\
\hline \multicolumn{5}{|c|}{ Laboratory investigation/Pathogenic organism } \\
\hline Absent & & $9(10.6)$ & $23(27.1)$ & 0 \\
\hline Present & & 0 & 0 & $53(62.3)$ \\
\hline Bacterial Vaginosis & & 0 & 0 & $21(24.7)$ \\
\hline Vaginal Candidiasis & & 0 & 0 & $17(20.0)$ \\
\hline Vaginal Trichomoniasis & & 0 & 0 & $15(17.6)$ \\
\hline Cervical cytology repor & $\operatorname{g~CIN~}$ & Negative & Negative & Negative \\
\hline
\end{tabular}

$\begin{array}{lllll}\text { Pak J Med Sci September-October } 2021 & \text { Vol. } 37 & \text { No. } 5 & \text { www.pjms.org.pk } 1305\end{array}$ 
$\mathrm{p}<0.0001)$, miscarriage $(\mathrm{n}=13, \mathrm{p}=0.009)$, preterm delivery $(\mathrm{n}=24, \mathrm{p}<0.0001)$ and post-partum endometritis $(\mathrm{n}=18, \mathrm{p}<0.0001)$ (Table-III). PVD was also statistically significantly associated with adverse neonatal outcomes: low birth weight $(\mathrm{n}=24, \mathrm{p}<0.0001)$, low Apgar score at birth $(\mathrm{n}=22, \mathrm{p}=0.0001)$, neonatal respiratory distress syndrome $(n=21, p<0.0001)$, neonatal intensive care hospitalization $(n=21, p, 0.0001)$ and early neonatal death $(\mathrm{n}=16, \mathrm{p}<0.0001)$ (Table-III).

Table-III: Adverse Maternal and Perinatal Outcomes Associated with Vaginal discharge during Pregnancy ( $\mathrm{N}=85)$.

\begin{tabular}{|c|c|c|c|c|c|c|}
\hline \multirow{3}{*}{ Maternal Outcomes } & \multirow{3}{*}{ Count } & \multirow{3}{*}{ Percentage } & \multicolumn{3}{|c|}{ Vaginal Discharge } & \multirow[t]{3}{*}{$P$ value } \\
\hline & & & \multirow{2}{*}{$\begin{array}{c}\text { No discharge only } \\
\text { perception }\end{array}$} & \multicolumn{2}{|c|}{ Yes } & \\
\hline & & & & Pathological & Physiological & \\
\hline \multicolumn{6}{|l|}{ Miscarriage } & $<0.009$ \\
\hline No & 72 & 84.7 & 9 & 40 & 23 & \\
\hline Yes & 13 & 15.3 & 0 & 13 & 0 & \\
\hline \multicolumn{6}{|l|}{ Uterine contractions } & $<0.0001$ \\
\hline No & 41 & 56.94 & 9 & 9 & 23 & \\
\hline Yes & 31 & 43.05 & 0 & 31 & 0 & \\
\hline \multicolumn{6}{|c|}{ Premature rupture of membranes } & $<0.0001$ \\
\hline No & 43 & 59.72 & 9 & 11 & 23 & \\
\hline Yes & 29 & 40.27 & 0 & 29 & 0 & \\
\hline \multicolumn{6}{|l|}{ Preterm delivery } & $<0.0001$ \\
\hline No & 48 & 66.7 & 9 & 16 & 23 & \\
\hline Yes & 24 & 33.3 & 0 & 24 & 0 & \\
\hline \multicolumn{6}{|c|}{ Postpartum endometritis } & $<0.0001$ \\
\hline No & 54 & 75 & 9 & 22 & 23 & \\
\hline Yes & 18 & 25 & 0 & 18 & 0 & \\
\hline \multicolumn{7}{|l|}{ Perinatal Outcomes } \\
\hline \multicolumn{6}{|l|}{ Low birth weight } & $<0.0001$ \\
\hline No & 48 & 66.7 & 9 & 16 & 23 & \\
\hline Yes & 24 & 33.3 & 0 & 24 & 0 & \\
\hline \multicolumn{6}{|c|}{ Low Apgar ${ }^{\dagger}$ Score at birth } & $<0.0001$ \\
\hline No & 50 & 69.4 & 9 & 18 & 23 & \\
\hline Yes & 22 & 30.6 & 0 & 22 & 0 & \\
\hline \multicolumn{6}{|c|}{ Neonatal respiratory distress syndrome } & $<0.0001$ \\
\hline No & 51 & 70.8 & 9 & 19 & 23 & \\
\hline Yes & 21 & 29.2 & 0 & 21 & 0 & \\
\hline \multicolumn{6}{|c|}{ Neonatal intensive care hospitalization } & $<0.0001$ \\
\hline No & 51 & 70.8 & 9 & 20 & 22 & \\
\hline Yes & 21 & 29.2 & 0 & 20 & 1 & \\
\hline \multicolumn{6}{|l|}{ Early neonatal death } & $<0.0001$ \\
\hline No & 56 & 77.78 & 9 & 24 & 23 & \\
\hline Yes & 16 & 22.22 & 0 & 16 & 0 & \\
\hline
\end{tabular}

†Apgar =Appearance, Pulse, Grimace, Activity, and Respiration. 


\section{DISCUSSION}

During pregnancy VD is common. Normal VD was not a major issue for women while pathological VD was a serious problem due to infection its symptomatology such as colour, quantity and odour parameters and associated complications. ${ }^{14}$

Causes of pathological vaginal discharge: In this study it was found that VD in pregnancy was most commonly pathological and it was due to three types of vaginal infections i.e. bacterial vaginosis, vaginal candidiasis and trichomoniasis vaginalis same is reported by other studies. ${ }^{15,16}$ The result of this study showed that bacterial vaginosis was the most common vaginal infection followed by vaginal candidiasis while trichomoniasis vaginalis was the least common vaginal infection in pregnant women with VD this is in consistent with other study. ${ }^{17}$

These vaginal infections are common in pregnant women with low level of education, underprivileged social and economic status and poor reproductive health hygiene. ${ }^{18}$ This study was conducted in public sector hospital outpatient Obstetrics and Gynaecology clinics where vast majority of patients attending these outpatient services belong to poor families, living in rural areas and slums, and often with low education. In addition, the average literacy rate of female in the country is low $(52 \%)$, which is even lower in rural areas (40.5\%). These factors are associated with low reproductive health hygiene in women. ${ }^{19}$ Moreover, females in Pakistan have less knowledge and practice of health hygiene and healthcare during menstruation, pregnancy, delivery and the postpartum period. More importantly, women living in rural areas of Pakistan have low healthcare seeking behavior during pregnancy, which is determined by social, economic and cultural factors. ${ }^{20-24}$

These factors may contribute to pathogenic vaginal infections i.e. BV, VC and TV and resultant PVD during pregnancy as identified in this study and in prior research. ${ }^{25}$ These infections and VD need proper investigation and appropriate treatment at the earliest to avoid any possible perinatal complications that may be associated with these vaginal infections. ${ }^{26,27}$ However there were no statistically significant differences detected in the preponderance of normal and PVD during pregnancy based on the women's age, gestation period and parity this is in consistent with other study. ${ }^{28}$

It was observed from the findings that in a higher proportion of pregnant women PVD was associated with adverse maternal and perinatal outcomes. The adverse maternal outcomes associated with PVD were vaginal irritation and pain, uterine contractions, premature membrane rupture, abortion, pre-term delivery and postpartum endometritis. ${ }^{29}$ The adverse perinatal outcomes significantly associated with PVD were low birth weight, low Apgar score at birth, neonatal respiratory distress syndrome, neonatal intensive care hospitalization and early neonatal death. ${ }^{25}$ These findings provide empirical evidence that PVD in pregnant women is associated with adverse perinatal outcomes this is in consistence with other study. ${ }^{29}$ PVD in pregnant women needs clinical investigation and relevant treatment. ${ }^{15}$ Proper management of vaginal infections and PVD during pregnancy may help in reducing the risk of adverse perinatal outcomes. ${ }^{29}$ that are very common in low middle income countries(LMICs) such as Pakistan. ${ }^{30}$

\section{CONCLUSION}

$\mathrm{VD}$ is common during pregnancy and it is essential to differentiate between normal VD and pathological VD during pregnancy. pathological VD is commonly due to vaginal infections such as bacterial vaginosis, candidiasis and trichomoniasis, which can be treated with appropriate treatment and avoided through information and advice for improving general health and reproductive health hygiene. In addition, early examination of vaginal discharge in pregnancy is needed to check for pathological VD to avoid associated adverse maternal and perinatal outcomes. Therefore, all the pregnant women with vaginal discharge should be investigated and treated appropriately.

Conflict of interest: All authors declare no conflict of interest.

Funding of study: Authors received no funding for this study.

\section{REFERENCES}

1. Von Glehn M de P, Sidon LU, Machado ER. Gynecological complaints and their associated factors among women in a family health-care clinic. J Family Med Prim Care. 2017;6(1):8892. doi: $10.4103 / 2249-4863.214982$

2. Rao VL, Mahmood T. Vaginal discharge. Obstet Gynaecol Reproduct Med. 2020;30(1):11-18. doi: 10.1016/j. ogrm.2019.10.004

3. Ilankoon IMPS, Goonewardena CSE, Fernandopulle R, Perera PPR. Women's understanding and cultural practices related to vaginal discharge: A qualitative study. Nursing Midwifery Stud. 2018;7(2):74-80.

4. Neal CM, Kus LH, Eckert LO, Peipert JF. Non candidal vaginitis: A comprehensive approach to diagnosis and management. Am J Obstet Gynecol. 2020;222(2):114-122. doi: 10.1016/j.ajog.2019.09.001 
5. Reiter S, Kellogg Spadt S. Bacterial vaginosis: a primer for clinicians. Postgrad Med. 2019;131(1):8-18. doi: 10.1080/00325481.2019.1546534

6. Coudray MS. Madhivanan P. Bacterial vaginosis-A brief synopsis of the literature. European J Obstet Gynecol Reproduct Biol. 2020;245:143-148. doi: 10.1016/j.ejogrb.2019.12.035

7. Goncalves B, Ferreira C, Alves CT, Henriques M, Azeredo J, Silva S. Vulvovaginal candidiasis: Epidemiology, microbiology and risk factors. Crit Rev Microbiol. 2016;42(6):905-927. doi: 10.3109/1040841X.2015.1091805

8. Bradford LL. Ravel J. The vaginal mycobiome: A contemporary perspective on fungi in women's health and diseases. Virulence. 2017;8(3):342-351. doi: 10.1080/21505594.2016.1237332

9. Coleman JS, Gaydos CA, Witter F. Trichomonas vaginalis vaginitis in obstetrics and gynecology practice: new concepts and controversies. Obstetr Gynecol Surv. 2013;68(1):43-50. doi: 10.1097/OGX.0b013e318279fb7d

10. Tellapragada C, Eshwara VK, Bhat P, Kamath A, Aletty S, Mukhopadhyay C. Screening of vulvovaginal infections during pregnancy in resource constrained settings: Implications on preterm delivery. J Infect Pub Health. 2017;10(4):431-437. doi: 10.1016/j.jiph.2016.06.003

11. Peelen MJ, Luef BM, Lamont RF, de Milliano I, Jensen JS, Limpens J, et al. The influence of the vaginal microbiota on preterm birth: A systematic review and recommendations for a minimum dataset for future research. Placenta. 2019;79:30-39. doi: 10.1016/j.placenta.2019.03.011

12. Khan N, Kausar R, Flach C, Howard L. Psychological and gynecological morbidity in women presenting with vaginal discharge in Pakistan. Int J Culture Ment Health. 2012;5(3):169181. doi: $10.1080 / 17542863.2011 .579710$

13. Saleem B, Jeelani SF, Sher SJ. Frequency of vaginal candidiasis in symptomatic pregnant women attending routine antenatal clinic. Pak J Med Health Sci. 2016;10(3):770-772.

14. Reichman O, Gal M, Leibovici V, Samueloff A. Evaluation of Vaginal Complaints During Pregnancy: The Approach to Diagnosis. Curr Dermatol Rep. 2014;3(3):159-164.

15. Obiero J, Rulisa S, Ogongo P, Wiysonge CS. NifuratelNystatin combination for the treatment of mixed infections of bacterial vaginosis, vulvovaginal candidiasis, and trichomonal vaginitis. Cochrane Database Syst Rev. 2018;2018(4):CD013012. doi: 10.1002/14651858.CD013012

16. Kalia N, Singh J, Kaur M. Microbiota in vaginal health and pathogenesis of recurrent vulvovaginal infections: A critical review. Ann Clin Microbiol Antimicrob. 2020;19:5 doi: 10.1186/s12941-020-0347-4

17. Liang Q, Li N, Song S, Zhang A, Li N, Duan Y. High-dose nifuratel for simple and mixed aerobic vaginitis: A singlecenter prospective open-label cohort study. J Obstet Gynaecol Res. 2016:42(10):1354-1360. doi: 10.1111/jog.13052

18. Abdul-Aziz M, Mahdy MAK, Abdul-Ghani R, Alhilali NA, Al-Mujahed LKA, Alabsi SA, et al. Bacterial vaginosis, vulvovaginal candidiasis and trichomonal vaginitis among reproductive-aged women seeking primary healthcare in Sana'a city, Yemen. BMC Infect Dis. 2019;19(1):879. doi: 10.1186/s12879-019-4549-3

19. Ali TS, Karmaliani R, Salam A, Ladak R, Moss N, Harris H, et al. Hygiene practices during menstruation and its relationship with income and education of women in Hyderabad, Pakistan. Pak J Womens Stud. 2006;13(2):185-199.

20. Michael J, Iqbal Q, Haider S, Khalid A, Haque N, Ishaq R, et al. Knowledge and practice of adolescent females about menstruation and menstruation hygiene visiting a public healthcare institute of Quetta, Pakistan. BMC Womens Health. 2020;20(1):4. doi: 10.1186/s12905-019-0874-3

21. Qazi U, Latif A, Irshad G, Malik FR, Anwar S. Assessment of birth preparedness and complication readiness among pregnant women attending the Obs/Gynae wards in two teaching hospitals in Peshawar, Khyber Pakhtunkhwa, Pakistan. Int J Gynecol Obstet. 2020;150(3). doi: 10.1002/ ijgo.13227
22. Sami N, Ali TS, Wasim S, Saleem S. Risk Factors for Secondary Infertility among Women in Karachi, Pakistan. Plos One. 2012;7(4):e35828. doi: 10.1371/journal.pone.0035828 25.

23. Qureshi RN, Sheikh S, Khowaja AR, Hoodbhoy Z, Zaidi S, Sawchuck D, et al. Health care seeking behaviours in pregnancy in rural Sindh, Pakistan: a qualitative study. Reprod Health 2016;13(1):34. doi: 10.1186/s12978-016-0140-1

24. Nnadi DC. Singh S. The prevalence of genital Candida species among pregnant women attending antenatal clinic in a tertiary health center in North-west Nigeria. Sahel Med J. 2017;20(1):3337. doi: $10.4103 / 1118-8561.204333$

25. Da Fonseca TMMV, Cesar JA, Mendoza-Sassi RA, Schmidt EB. Pathological vaginal discharge among pregnant women: pattern of occurrence and association in a populationbased survey. Obstetr Gynecol Int. 2013:590416. doi: $10.1155 / 2013 / 590416$

26. Freitas AC, Chaban B, Bocking A, Rocco M, Yang S, Hill JE, et al. The vaginal microbiome of pregnant women is less rich and diverse, with lower prevalence of Mollicutes, compared to non-pregnant women. Sci Rep. 2017;7(1):9212. doi: 10.1038/ s41598-017-07790-9

27. Abdelaziz ZA, Ibrahim ME, Bilal NE, Hamid ME. Vaginal infections among pregnant women at Omdurman Maternity Hospital in Khartoum, Sudan. J Infect Develop Count. 2014;8(4):490-497. doi: 10.3855/jidc.3197

28. Isik G, Demirezen S, Donmez HG, Beksac MS. Bacterial vaginosis in association with spontaneous abortion and recurrent pregnancy losses. J Cytol. 2016;33(3):135-140. https://www.jcytol.org/text.asp?2016/33/3/135/188050

29. Bonet M, Brizuela V, Abalos E, Cuesta C, Baguiya A, Chamillard $M$, et al. Frequency and management of maternal infection in health facilities in 52 countries (GLOSS): a 1-week inception cohort study. Lancet Global Health. 2020;8(5):e661-e671. doi: 10.1016/S2214-109X(20)30109-1

30. Anwar J, Torvaldsen S, Sheikh M, Taylor R. Under-estimation of maternal and perinatal mortality revealed by an enhanced surveillance system: enumerating all births and deaths in Pakistan. BMC Public Health. 2018;18 (1):428. doi: 10.1186/ s12889-018-5363-3

\section{Author's Contribution:}

MK: Conception, design, study conducted, Manuscript writing.

SB: Acquisition of data, Manuscript review.

ASB: Data collection and Interpretation.

SGSS: Analyses of data \& Drafting and critically revised.

Authors:

1. Meharunnissa Khaskheli, MBBS, FCPS. Department of Obstetrics and Gynecology,

2. Shahla Baloch, MBBS, DGO, FCPS Department of Obstetrics and Gynecology,

3. Aneela Sheeba Baloch, MBBS, DMRD, FCPS. Department of Radiology

4. Syed Ghulam Sarwar Shah, MBBS, MSc, PhD. NIHR Oxford Biomedical Research Centre, Oxford University Hospitals NHS Foundation Trust, John Radcliffe Hospital,

Headington Way, Headington, Oxford, OX3 9DU, England, UK. Radcliffe Department of Medicine, University of Oxford, John Radcliffe Hospital, Headington Way, Headington, Oxford, OX3 9DU, England, UK.

1-3: Liaquat University of Medical and Health Sciences, Liaquat University Hospital, Jamshoro, Hyderabad, Sindh, Pakistan. 